\title{
DOSSIÊ: SEMINÁRIO CIÊNCIA DA CONSERVAÇÃO E O USO DE CARACTERIZAÇÃO QUÍMICA, FÍSICA E BIOLÓGICA DE BENS CULTURAIS
}

CIBELE MONTEIRO DA SILVA, UNIVERSIDADE DE SÃO PAULO, SÃO PAULO, SÃO PAULO, BRASIL. Especialista em pesquisa e apoio de museu do Centro de Preservação Cultural da Universidade de São Paulo (CPC-USP)

E-mail: cpc2@usp.br

DOI

http://dx.doi.org/10.11606/issn.1980-4466.v0i23p202-206 
O seminário "Ciência da conservação e o uso de caracterização química, física e biológica de bens culturais" foi resultado de uma parceria estabelecida entre o Centro de Preservação Cultural da Universidade de São Paulo (CPC-USP), a Escola de Artes, Ciências e Humanidades da USP (EACH-USP) e a Universidade Federal de Pelotas (UFPel), representados por Cibele Monteiro, especialista em pesquisa e apoio de museu do CPC -USP, pelo professor Andrea Cavicchioli, da EACH-USP, e pelo professor Thiago Puglieri, da UFPel.

A proposta de realização do evento parte do reconhecimento de profícuas parcerias entre os pesquisadores e professores das áreas de química, física e biologia e as instituições e profissionais envolvidos com a preservação de bens culturais, reconhecendo-se, ainda, a pouca divulgação dessas parcerias e das pesquisas desenvolvidas no campo do patrimônio cultural.

O evento aconteceu no dia 25 de agosto de 2016, com palestras expositivas na parte da manhã que apresentaram, de maneira geral, as teorias e conceitos desenvolvidos pelos pesquisadores das ciências naturais no que toca à conservação do patrimônio móvel.

As palestras foram proferidas por professores de diversas áreas das ciências naturais, iniciando-se com a fala do prof. dr. Luiz Antônio Cruz Souza, do Centro de Conservação e Restauração de Bens Culturais da 
Universidade Federal de Minas Gerais (CECOR-UFMG), com o título "Ciência da conservação e seu desenvolvimento com técnicas de caracterização no Brasil e no mundo", como embasamento conceitual para as palestras que viriam a seguir.

Em seguida, a profa. dra. Márcia Rizzutto, do Departamento de Física Nuclear do Instituto de Física da USP (IF-USP), cujo enunciado, "Principais técnicas de imageamento e de caracterização elementar em conservação de bens culturais", abordou as investigações científicas e técnicas do campo da física, utilizados nos estudos e análises de objetos de arte e do patrimônio histórico cultural.

A profa. dra. Dalva de Faria, do Instituto de Química da USP (IQ -USP), que discorreu sobre as "Principais técnicas de caracterização molecular e de imageamento químico em conservação de bens culturais", tratou da conservação de bens culturais a partir do conhecimento da composição química desses bens e do ambiente que os cinge.

A questão do controle climático ambiental foi desenvolvida na fala do prof. dr. Andrea Cavicchioli, da Escola de Artes, Ciências e Humanidades da USP (EACH-USP), que propôs uma discussão a respeito das principais abordagens para a realização de diagnósticos e controle ambientais na perspectiva da conservação preventiva, sob o título "Principais tecnologias para caracterização e alerta precoce de agressividade ambiental e caracterização biológica aplicada em conservação de bens culturais".

No fechamento das palestras expositivas, a profa. dra. Eliane Aparecida Del Lama, do Instituto de Geociências da USP (IGc-USP), apresentou as pesquisas desenvolvidas em torno dos monumentos e edifícios confeccionados em pedra presentes na cidade de São Paulo, na palestra intitulada "Análise do estado de conservação e as formas de alteração nos monumentos pétreos da cidade de São Paulo".

Na parte da tarde, foram expostos estudos de casos que mostraram proveitosas colaborações entre os especialistas em ciência da conservação e os profissionais e de instituições ligadas ao patrimônio cultural, revelando como essas associações ocorrem na prática, demonstrando quais os desafios encontrados e os resultados dessas cooperações.

A primeira parceria, "Impacto da composição química de microambientes em bens culturais: o caso do MAC-USP e do Museu do Orató- 
rio, MG", foi apresentada pelo prof. dr. Thiago Sevilhano Puglieri (UFPel) e Ariane Lavezzo, conservadora e restauradora de pintura e escultura do Museu de Arte Contemporânea da USP (MAC-USP), que abordaram dois estudos de caso abarcando o uso de ferramentas de caracterização química para depreender o impacto da composição química de microambientes em bens culturais.

O prof. dr. Pablo Vásquez, do Instituto de Pesquisas Energéticas e Nucleares (IPEN), e Eliana de Azevedo Marques (FAU-USP), apresentaram "Preservação e conservação de materiais de patrimônio cultural utilizando radiação ionizante: a parceria com a Biblioteca da FAU-USP”, em que foram expostas as diversas parcerias entre o Centro de Tecnologia das Radiações do Instituto de Pesquisas Energéticas e Nucleares (CTR-IPEN), e instituições da Universidade de São Paulo, particularmente a Faculdade de Arquitetura e Urbanismo da USP (FAU-USP), onde foram tratados desenhos originais e materiais bibliográficos que sofreram com ataque de microrganismos.

Ao final, foi organizada uma mesa redonda com a mediação da dra. Teresa Cristina Toledo de Paula, conservadora e restauradora de têxteis do Museu Paulista da USP (MP-USP) e pesquisadora permanente do Instituto de Estudos Avançados da USP (IEA-USP), que mediou o debate que contribuiu no aprofundamento de algumas das questões apresentadas, e nas discussões sobre quais seriam as perspectivas de entrosamento das áreas e difusão dos conhecimentos desenvolvidos.

O evento expôs pesquisas e trabalhos produzidos no âmbito da Universidade de São Paulo e contou com a participação de renomados docentes e especialistas da USP e da UFMG e UFPel, em virtude do destaque desses profissionais no cenário científico nacional, no que tange à conservação de bens culturais.

O caráter inédito do evento foi comentado na fala de abertura do prof. dr. Marcelo de Andrade Roméro, pró-reitor de Cultura e Extensão Universitária, e reiterado nas falas da profa. Mônica Junqueira de Camargo e Ppofa. Maria Cristina Motta de Toledo, diretoras do CPC-USP e EA$\mathrm{CH}$-USP, respectivamente, bem como o reconhecimento da importância do evento no desenvolvimento de pesquisas interdisciplinares.

Tal importância é reforçada pela grande procura do evento e pela 
presença de uma plateia composta por profissionais da área de museus, bibliotecas e arquivos, assim como diretores de instituições culturais e interessados provenientes de diversas áreas.

O evento teve o apoio da FAU-USP, que cedeu o auditório Ariosto Milla mediante a solicitação do CPC por conta dos mais de 300 inscritos no seminário. A Sala dos Espelhos da FAU-Maranhão, onde o evento a princípio ocorreria, não comportaria o grande número de participantes.

Um dos resultados do seminário é a produção e publicação de alguns artigos, produzidos a partir do Seminário, na presente edição da Revista CPC. 